Natural and Applied Sciences International Journal (NASIJ) eISSN: 2788-4619 (Online)

https://doi.org/10.47264/idea.nasij/2.1.1

Vol. 2, No. 1, (January-December 2021), 1-11

https://www.ideapublishers.org/index.php/nasij

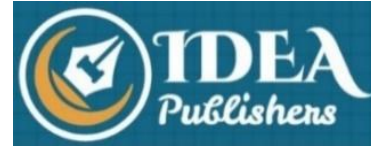

Research Article

\title{
Remote sensing analysis of unnamed crater in Eastern Australia
}

Zahid U. Rahman*

Department of Computer Science, Comsats University, Islamabad, Pakistan.

* Corresponding Author Email: zahidktk369@gmail.com

Published Online: August 3, 2021

\begin{abstract}
Remote sensing (RS) can certainly provide deep insights about detecting the terrestrial structure of unknown origin. In this paper, we also detected impact crater of unknown origin in northeast Australia by RS techniques, specifically to enhance the credibility of scientific database on the possible impact craters in the continent of Australia. Following the RS procedures, a circularshaped unnamed crater, hereafter the Winton crater, was detected with a diameter of approximately $130-\mathrm{km}$. Furthermore, the topographical parameter was obtained from RS data, which showed that the area, depth and volume of the crater are $~ 100-\mathrm{m} 2, \sim 130-\mathrm{m}$ and $~ 99.8-\mathrm{m} 3$, respectively. The geological data revealed that inside the crater, the outcrops are mainly consisted of sedimentary and low grade metamorphic rock, specifically included the mixed sediments and conglomerates, limestone and siltstone of the Craterous period. However, the exterior of the circular shaped in the southern part is consisted of unconsolidated deposits of the Tertiary period. The positive value of gravity anomaly for the major part of the crater is 3000 $\mathrm{mGal}$ and Bouguer gravity onshore grid has an anomaly of $900 \mathrm{mGal}$ over the impact crater. It showed that the Winton crater could not be the due to any volcanic or karstic processes. On the other hand, a detailed field and petrology investigation should need to distinguish the origin of the crater of old and fossil travertine or an impact crater.
\end{abstract}

Keywords: Australia, Winton, impact crater, geology, geophysics, remote sensing, bouguer.

\section{How to Cite:}

Rahman, Z. U. (2021). Remote sensing analysis of unnamed crater in Eastern Australia. Natural \& Applied Sciences International Journal (NASIJ), 2(1), 1-11. https://doi.org/10.47264/idea.nasij/2.1.1

\section{Publisher's Note:}

IDEA PUBLISHERS (IDEA Journals Group) stands neutral regarding jurisdictional claims in the published maps and institutional affiliations.

\section{Copyright:}

(C) 2021 The Author(s), published by IDEA PUBLISHERS (IDEA Journals Group)

This is an Open Access article published under the Creative Commons Attribution-NonCommercial 4.0 International License (http://creativecommons.org/licenses/by-nc/4.0/) 


\section{Introduction}

The rapid recognition of detecting extra-terrestrial impacts in the form of common geological procedures and the increasing attention to newly recognized crater structures have prompted various researches for new structures in the form of adequate mapping of different procedures with RS and geophysical surveys (French, 1998). The primary goal of RS techniques is to offer a meaningful information about the terrestrial structures prior to fieldwork (both geological and geophysical), geographical field, sample collection, and further analysis in the areas, where there is a lack of or no access to field work (Wright et al., 2013). In this regard, the images from the Google Earth ${ }^{\mathrm{TM}}$ has provided a chance to implement the study of the impact structure reports (Pati \& Reimold, 2007).

There are nominal studies in the literature on RS procedures for detecting terrestrial structures of new impact craters (Garvin et al., 1992; Koeberl, 2004; Folco et al., 2010; 2011). Within that studies, a variety of different RS procedures were adopted to determine the topographical pattern, geological setting, geographical environment and geophysical anomalies. The impact craters were usually identified by some distinct features; the bowl-shaped circular rim features and an anomalous gravity value around the crater (French \& Koeberl, 2010). During the last decade, RS procedures turned out to be fruitful in finding new possible impact craters (Koeberl \& Reimold, 2005; Buchner \& Kenkmann, 2008). Furthermore, it provided more insights about research on new possible impact craters (Grieve, 2005; Reimold et al., 2006). In this regard, the amalgamation of geographical, topographical, geological, geophysical and in situ fieldwork data was analyzed to detect the new possible impact composite structure such as the Arkenu Libya (Paillou et al., 2003), and the Gilf Kebir in Egypt (Paillou et al., 2004).

Apart from other literature research of the RS procedures of impact craters, some on the RS procedures were deployed on the Landsat Thematic Mapper imageries (Gad \& Kusky, 2006), global Digital Elevation Model (DEM) (Schmieder et al., 2013), compilations of Bouguer anomaly over craters (Heinrichs et al., 2014), and Advanced Space-borne Thermal Emission and Reflection Radiometer sensor (Wright et al., 2013). In the meantime, detecting a perfectly circular and locally different impact features, RS and geophysical procedures, both become effective for the initial detection of possible impact structures (Pati et al., 2009). Recently, the applications of RS got much attention to disclose the doubted impact structures specifically in the inaccessible far regions. For example, the RS techniques were adopted by Mars and Rowan (2010) for studying different features of a volcanic crater in Afghanistan, including the spectral analysis and lithological mapping of the crater structure.

However, these procedures were not used to find out other terrestrial features in the region of Afghanistan. About the possible impact craters in Australia, Glikson et al. (2016) has written a research article about the circular drainage pattern of the Diamantina $\sim 120-\mathrm{km}$ diameter ring feature. The authors of this research study have examined different geophysical data in the source area, including, total magnetic intensity, gravity and seismic reflection transect from the vicinity of the ring feature to help test the origin of the structure. However, a potential interpretation about the acceptance or rejection of an asteroid impact crater were not exposed based on the RS and the other geophysical procedures. In this research study, we aimed to detect a possible unnamed impact crater in northeastern Australia based the RS and other geophysical data. We also presented further details of the study area based on the global DEM and the geological data. 


\section{General information of the study area}

The Winton crater was recorded as an 'unnamed crater' by the catalogue of global terrestrial impact craters (Wikipedia, n.d) and later placed as 'unconfirmed crater' in the list of unconfirmed impact craters hosted by the Wikiwand (n.d). According to the global impact crater database, there are eight unconfirmed and unnamed impact craters in Australia. Among them, the Winton crater located in the northeast of Australia, which was first presented by Glikson et al. (2016). The other unconfirmed and unnamed impact craters can be accessed by the world list of unnamed terrestrial craters via Wikiwand (n.d).

Figure 1: (a) Geographical location of the Winton Crater exclusively, and (b) the Winton Crater on the map of Australia

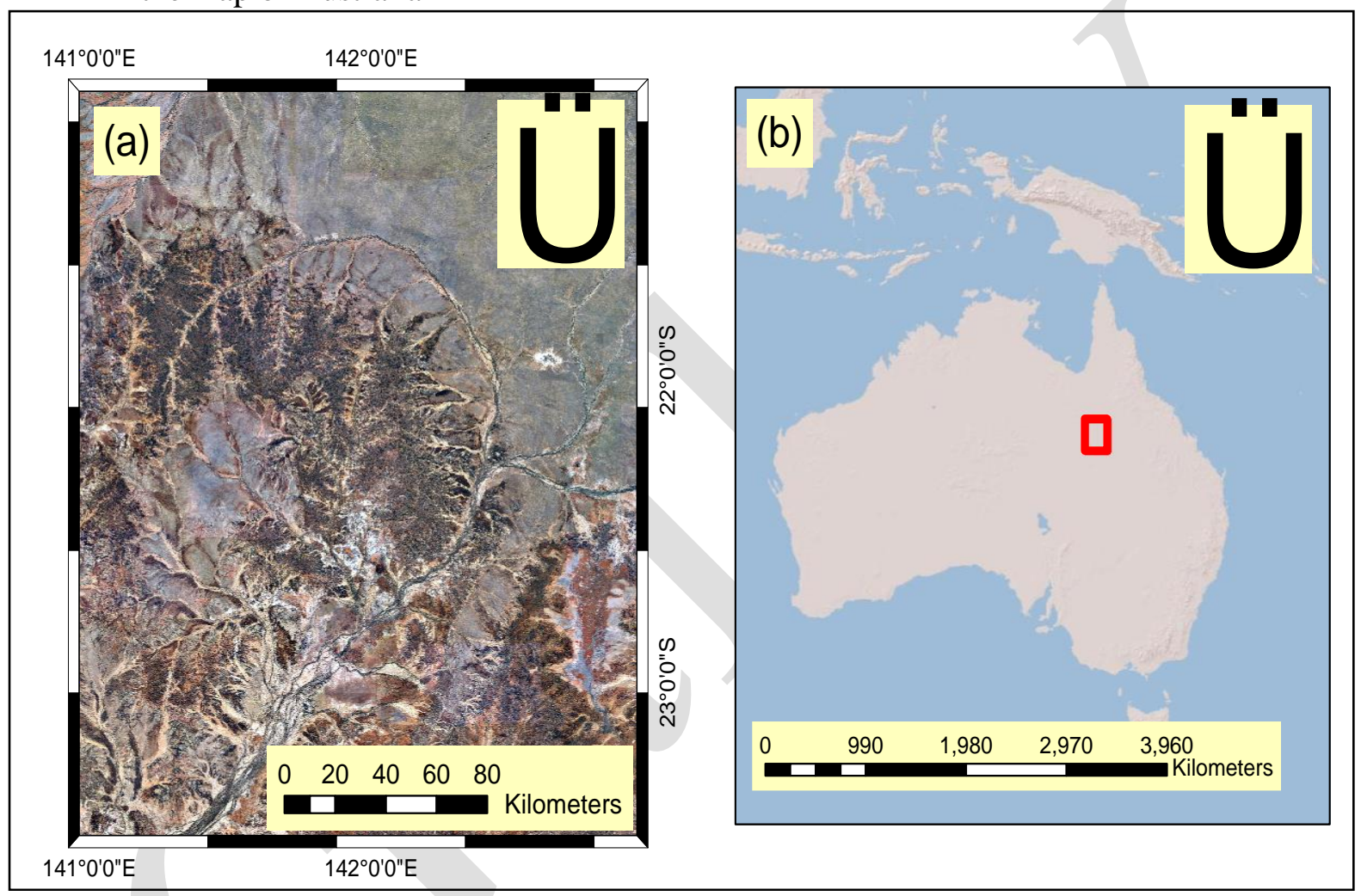

The crater in this study was named as 'Winton crater', having a diameter of $130 \mathrm{~km}$ and a depth of $\sim 120 \mathrm{~m}$. It is located between latitude $21^{\circ} 0^{\prime} 0^{\prime \prime} \mathrm{N}$ to $23^{\circ} 0^{\prime} 0^{\prime \prime} \mathrm{N}$ and longitude $141^{\circ} 0^{\prime} 0^{\prime \prime} \mathrm{E}$ to $143^{\circ} 0^{\prime} 0^{\prime \prime} \mathrm{E}$ in the Queensland state in northeastern Australia (Figure 1). The crater is located near the boarders of the Northern Territory, South Australia and New South Wales. The study area has a subtropical climate with significant variation in different months of the year. According to World Clim database during 1950-2000 (Hijmans et al., 2005), the mean annual precipitation and temperature of the study area are $400 \mathrm{~mm}$ and $19^{\circ} \mathrm{C}$, respectively.

\section{Retrieval of data}

According to Daneshvar et al. (2013), the impact crater circular symmetry must fulfill the circular shape of the topography, morphological structures, geological profile and deformation pattern, and have characteristics geophysical anomalies. In this regard, a RS study was conducted to confirm the topographical, geological and geophysical properties of the Winton 
crater data retrieved from GIS processes. The geographical information and other properties of the impact crater was obtained from the global impact crater database via Wikiwand (n.d). The location map of the crater was obtained from Google Earth and later georeferenced in ArcGIS (Figure 1). According to Raymond and Retter (2010), the surface geological raster layer of Australia at 1: 1,000,000 Scale, 2010 edition was retrieved from the Atlas of living Australia (Atlas of living Australia, n.d). Similarly, the topographical profiles were constructed from the Advanced Space-borne Thermal Emission and Reflection Radiometer, Global Digital Elevation Model (ASTER, GDEM) data obtained from NASA spacecraft Terra. The ASTER GDEM having a horizontal resolution of $75 \mathrm{~m}$ are extracted from Earth Explorer (n.d) and it was compiled in the form of Georeferenced Tagged Image File Format (GeoTIFF) documents having the accuracy of $17 \mathrm{~m}$ at $95 \%$ confidence level. On the other hand, the Gravity Anomaly and Bouguer Anomaly data were obtained from the Australian government.

\section{Results and discussion}

In this paper, the RS procedures were implemented on the Winton Crater to update the global terrestrial impact craters. The digital elevation model of the study area showed the crater between the elevation intervals of $-48 \mathrm{~m}$ and $100 \mathrm{~m}$ (Figure 2). From the DEM analysis, it can be seen that the crater has a circular and bowl-shape geometry with a depth of approximately $\sim 120 \mathrm{~m}$ and a circular diameter of $130 \mathrm{~km}$. The rim and circular-shaped pattern of the impact crater is prominent from the surrounding regions in the satellite based DEM image.

Figure 2: ASTER GDEM profile of the study with a circle indicating the position of the impact crater

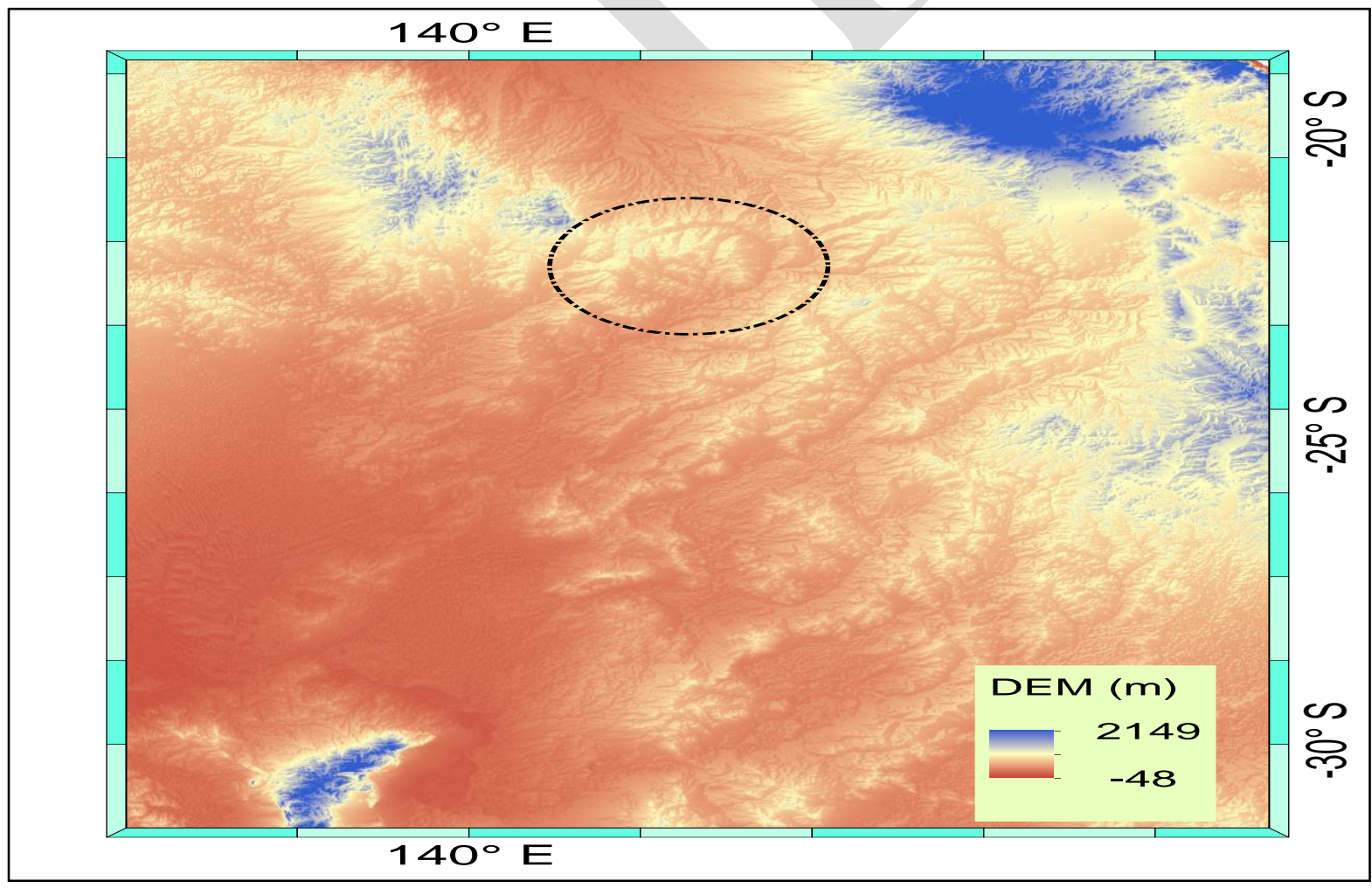

According to (Passchier \& Williams, 1989; Tucker, 2014), the crater is mainly exposed in the sedimentary and low grade metamorphic rock, specifically, comprised the mixed sediments/conglomerates, limestone and siltstone of the Craterous period. Inside the crater, the 
northeast part of the crater mainly consisted of mixed sediments/conglomerates of the Craterous period, whereas the southern part has partially unconsolidated deposits of the Tertiary period. On the other hand, the exterior of the crater rim has been covered mainly by mixed sediments of the Craterous and some mixed sediments formed by complex faulting in the Devonian period (Figure 3). Some NW-SE trending fault lineaments were found outside the crater in the Devonian Period, which cracked the host rocks without altering any lithological units. The surface geology of the interior and thus the exterior of the crater are found in a distinct lithological unit, which can be the evidence for the existence of a possible impact crater in the study area. These geological results proved that the Winton crater could neither be the result of an igneous nor a Karstic production caused by carbonate formations. According to Blair (1986), the Karstic crater formed in the formations where the purity of limestone would be above $95 \%$.

Figure 3: Geological map of the study area obtained from the Atlas of living Australia. The characters C, T and D, are representing the Cretaceous, Tertiary and Devonian period, respectively

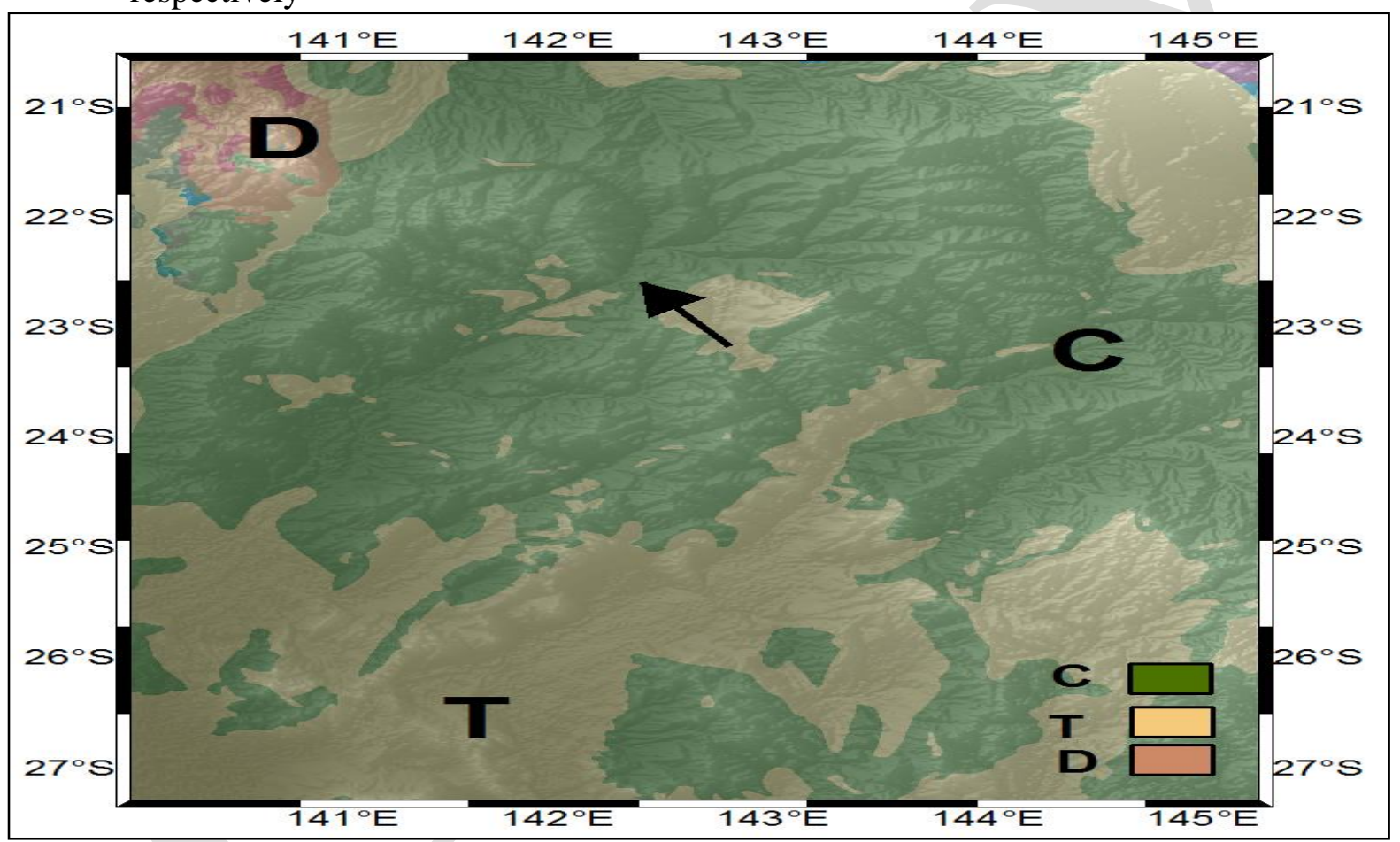

According to RS study, the crater is possessed by positive Bouguer and gravity anomalies, which also revealed the existence of an impact crater rather than carbonate process formation. The positive value of gravity anomaly for the major part of the crater is $3000 \mathrm{mGal}$ (Figure 4). On the other hand, the Bouguer gravity onshore grid has an anomaly of $900 \mathrm{mGal}$ over the impact crater region (Figure 5). Figure 5 also reveals that inside the crater, the bedrocks have high density sediments and deposition except the northeast part, where the gravity anomaly has negative value. According to French and Koeberl (2010), small impact craters having a diameter less than $10 \mathrm{~km}$ usually show negative gravity anomalies indicating the presence of less dense sediment deposits in the crater structure. In this case, our RS study confirmed the high density bedrocks inside the crater. However, to confirm the impact crater from old and fossil travertine, a comprehensive field work should need to be done, because travertine overlap with minerals may be injected to deeper strata, complex fault lineaments or fossils mixture. 
Figure 4: Gravity anomaly grid of Queensland over the Winton crater from the Geosciences Australia homepage.

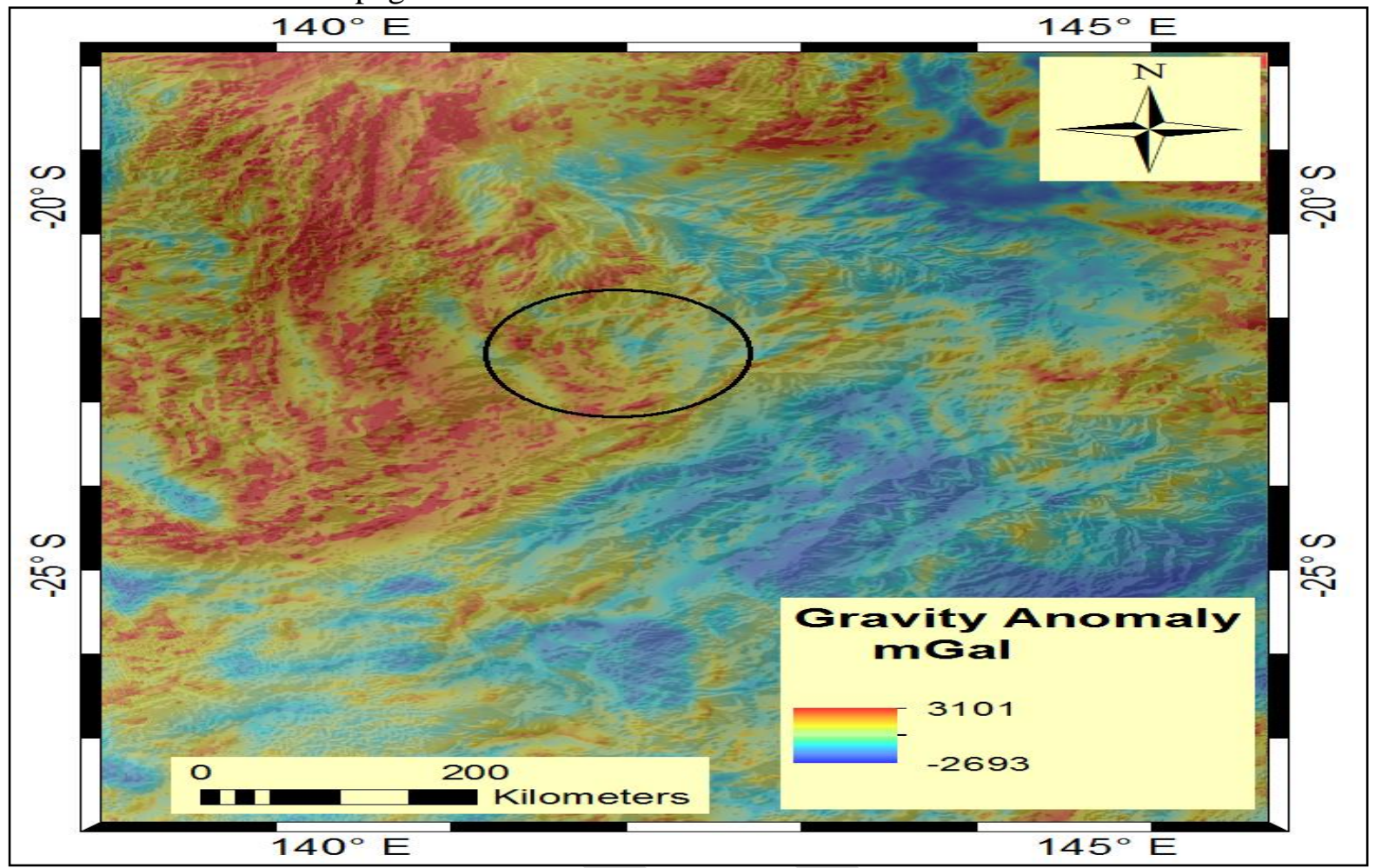

Figure 5: The spatial Bouguer anomaly over the study area, retrieved from the Geosciences Australia homepage

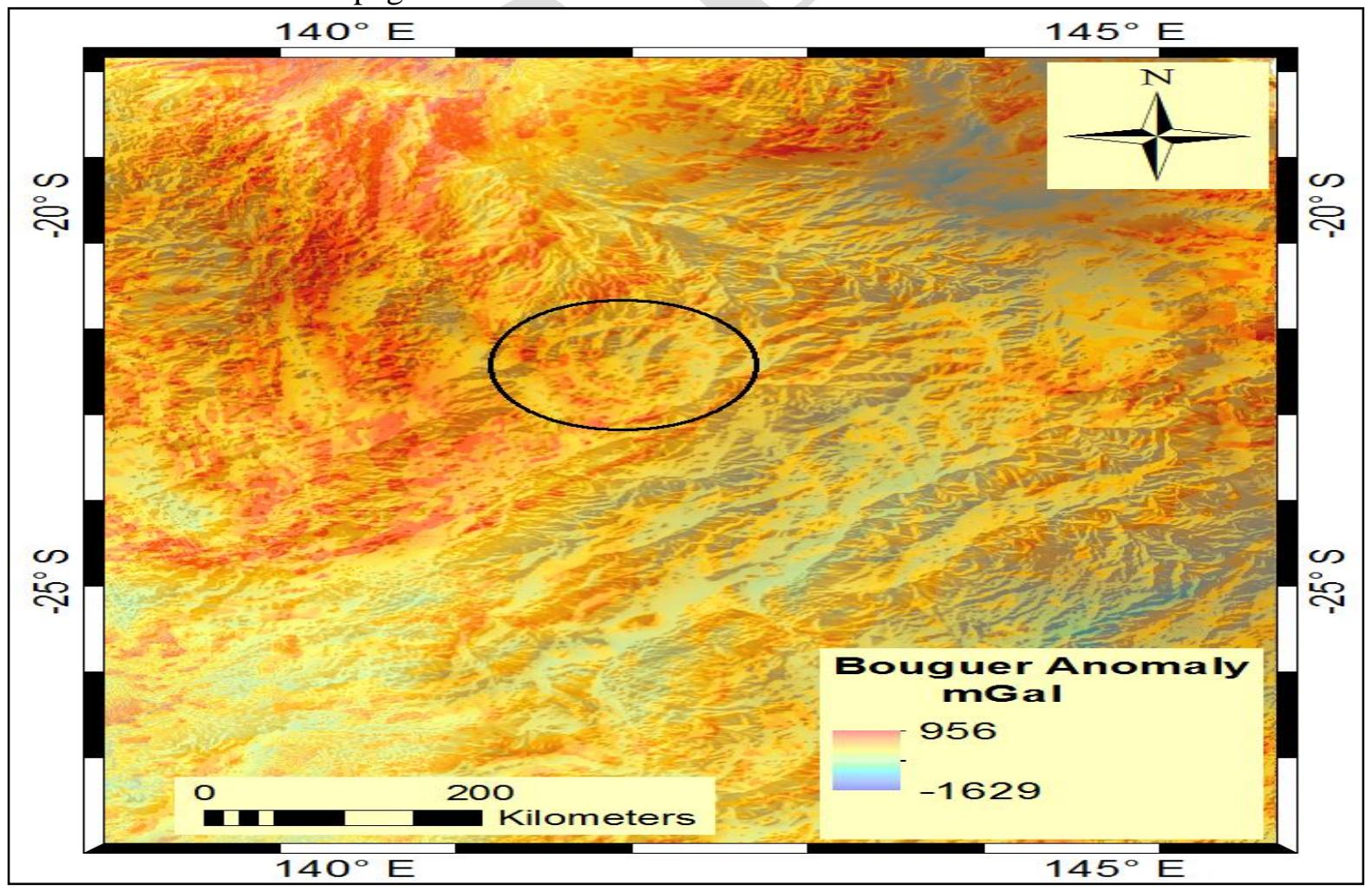


The DEM profiles from north to south and east to west showed a dominant structure confirming the crater along the regional catchment water flow. The profiles confirmed the circular, bowlshaped geometry and rim projections of the crater on DEM, having identical topographic shape as that of an impact crater (Figure 6).

Figure 6: The topographical profiles of two cross-sections on DEM

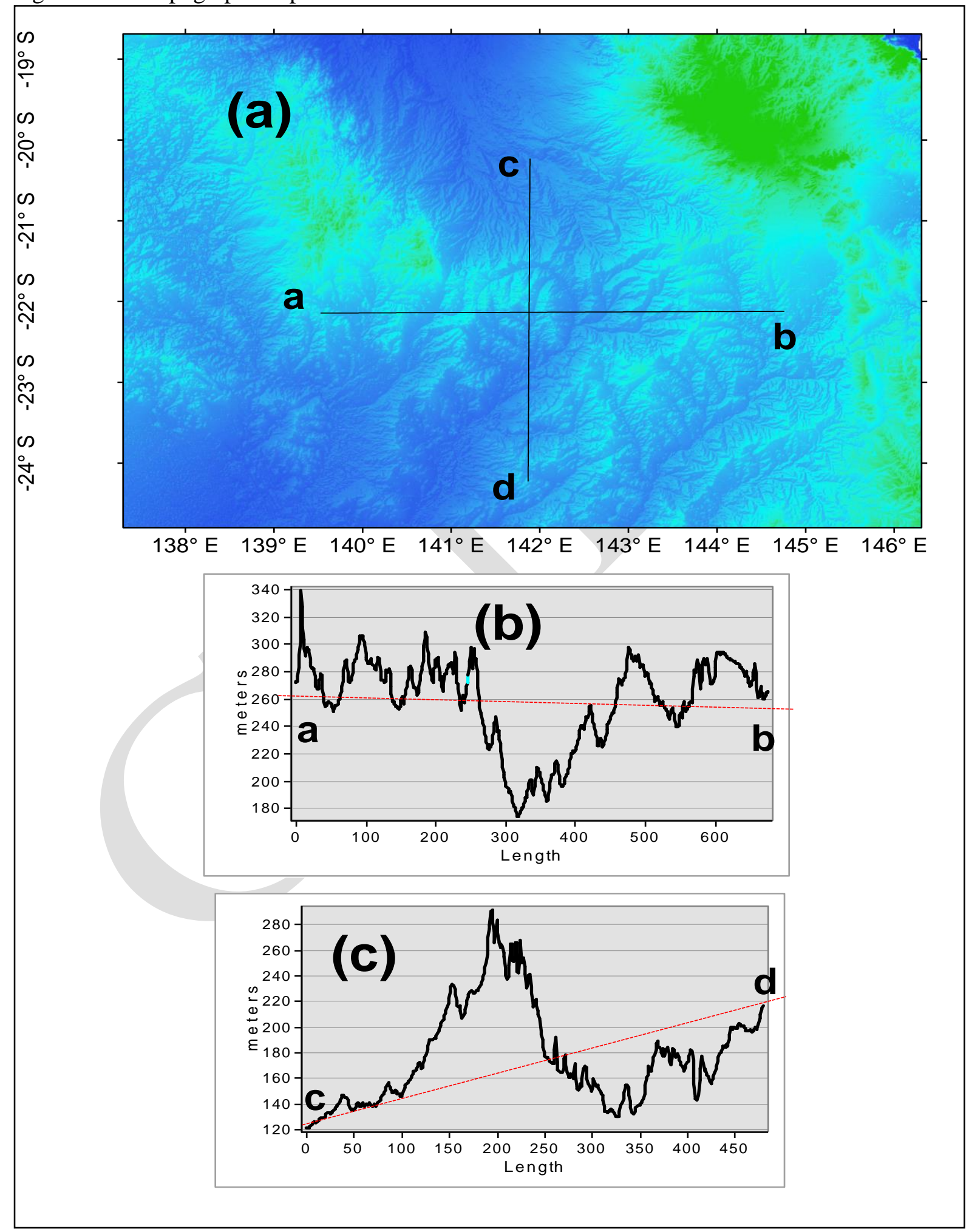


The depth and diameter of the interior ring of the crater were confirmed to $\sim 120 \mathrm{~m}$ and $\sim 130$ $\mathrm{km}$, respectively. The profiles based circular pattern may be assumed to be a possible impact crater, however, it needs further confirmation from a detailed geological and geophysical interpretation. Similar features could be formed by different conventional processes such tectonic deformation, salt dome formation, igneous fragmentation, volcanic activities, karstic occurrences and erosion activities (Daneshvar et al., 2013).

Figure 7: Volume from elevation point for the interior of the crater

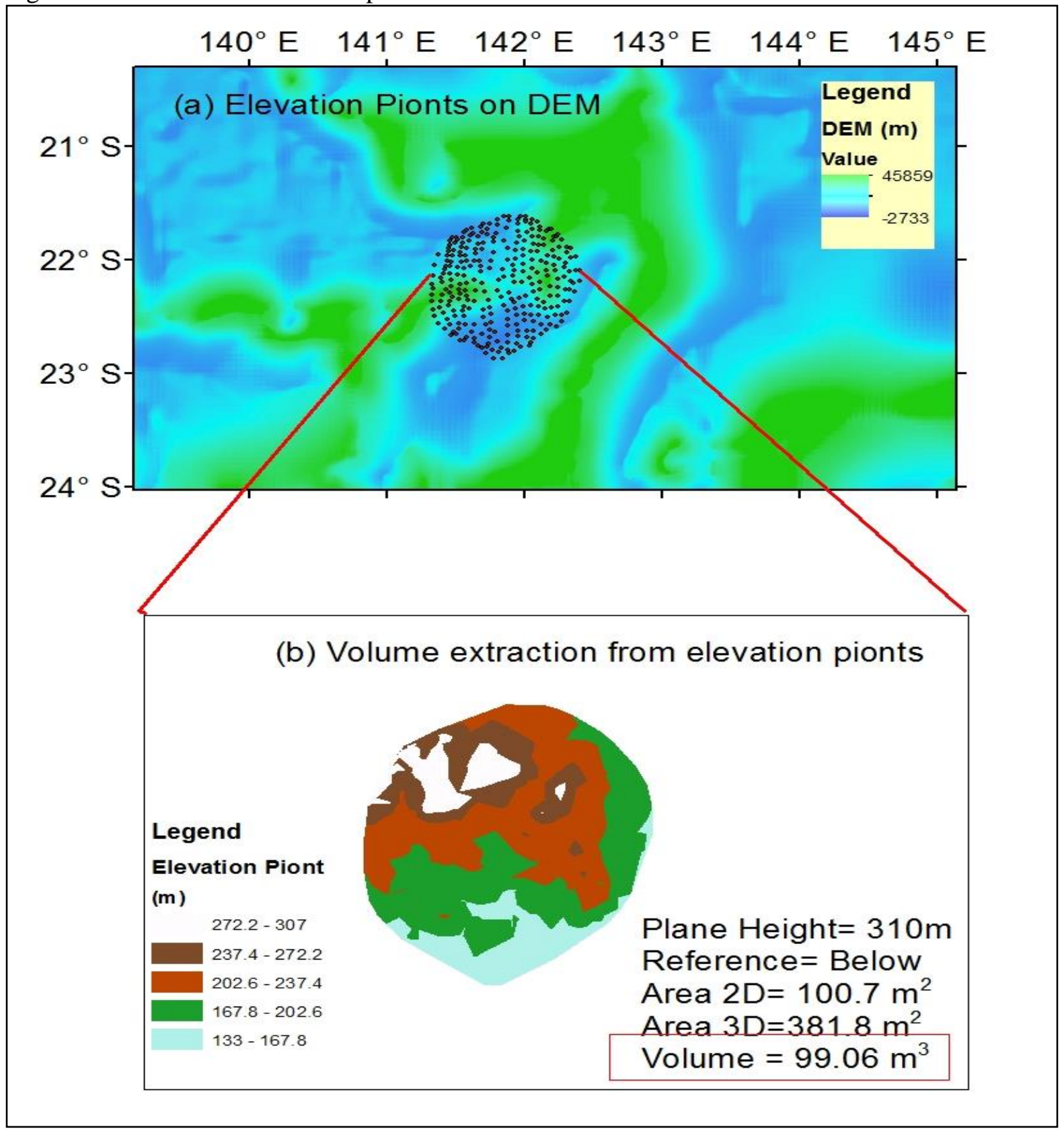

In this study, we calculated the volume of the Winton crater by RS procedures to further update the list of information and attract new research about this unknown crater. For this purpose, the elevation points were extracted from Google Earth $^{\mathrm{TM}}$ and process in ArcGIS to have a raster volume for the interior of the crater (Figure 7). The volume calculated from the elevation points 
was $~ 99.8 \mathrm{~m}^{3}$. According to Wang et al. (2017), the volume estimation based on RS is an important procedure in the determination of the morphometric study of impact craters because it is important in valuing the early erosion process of the terrestrial and lunar craters. However, more detailed fieldwork and high-resolution photography could certainly prove the RS procedures of the impact crater.

\section{Conclusion}

In this paper, RS procedures were adopted to enhance the information in the global terrestrial database about the Winton crater. A detailed RS analysis was done based on topographical, geophysical and geographical procedures. The satellite imagery and topographical data confirmed the circular bowl shaped of the crater, whereas the geographical and geophysical data confirmed the origin of an impact crater. Furthermore, the topographical parameter was obtained from RS data, which showed that the area, depth and volume of the crater are $~ 100$ $\mathrm{m}^{2}, \sim 130-\mathrm{m}$ and $\sim 99.8-\mathrm{m}^{3}$, respectively. The geological study revealed that the crater is mainly exposed in the sedimentary formations of the Craterous period, however detailed field work would confirm it. Additionally, the geophysical data confirmed that the crater is made up of high density rock which is not possible by any igneous or other morphological activity. The origin of the crater may or may not be the impact carter. But, the RS procedures in this study certainly improved the scientific database and geo-visualization data of the Winton crater.

\section{Acknowledgement}

The authors are very grateful to Geoscience Australia and Atlas of living Australia for the spatial data. This research is not funded by any organization.

\section{References}

Atlas of living Australia. (n.d). Spatial Layers. http://spatial.ala.org.au/layers

Blair R.W. Jr. (1986) Karst landforms and lakes. In N. M. Short Sr. \& R. W. Blair Jr. (Eds.), Geomorphology from space: A global overview of regional landforms (pp. 402-446). Washington DC: NASA Special Publication (SP-486)

Buchner, E., \& Kenkmann, T. (2008). Upheaval Dome, Utah, USA: Impact origin confirmed. Geology, 36(3), 227-230. https://doi.org/10.1130/G24287A.1

Earth Explorer. (nd). USGS. https://earthexplorer.usgs.gov/

Folco, L., Di Martino, M., El Barkooky, A., D'Orazio, M., Lethy, A., Urbini, S., ... \& El Sharkawi, M. (2010). The kamil crater in Egypt. Science, 329(5993), 804-804. https://science.sciencemag.org/content/329/5993/804.abstract

Folco, L., Di Martino, M., El Barkooky, A., D'Orazio, M., Lethy, A., Urbini, S., ... \& El Sharkawi, M. (2011). Kamil Crater (Egypt): Ground truth for small-scale meteorite impacts on Earth. Geology, 39(2), 179-182. https://doi.org/10.1130/G31624.1

French, B. M. (1998). Traces of catastrophe: A handbook of shock-metamorphic effects in terrestrial meteorite impact structures. Lunar and Planetary Institute.

French, B. M., \& Koeberl, C. (2010). The convincing identification of terrestrial meteorite impact structures: What works, what doesn't, and why. Earth-Science Reviews, 98(12), 123-170. https://doi.org/10.1016/j.earscirev.2009.10.009 
Gad, S., \& Kusky, T. (2006). Lithological mapping in the Eastern Desert of Egypt, the Barramiya area, using Landsat thematic mapper (TM). Journal of African Earth Sciences, 44(2), 196-202. https://doi.org/10.1016/j.jafrearsci.2005.10.014

Garvin, J. B., Schnetzler, C. C., \& Grieve, R. A. (1992). Characteristics of large terrestrial impact structures as revealed by remote sensing studies. Tectonophysics, 216(1-2), 45-62. https://doi.org/10.1016/0040-1951(92)90155-Y

Glikson, A., Korsch, R. J., \& Milligan, P. (2016). The Diamantina river ring feature, Winton region, Western Queensland. Australian Journal of Earth Sciences, 63(5), 653-663. https://doi.org/10.1080/08120099.2016.1220978

Grieve, R. A. (2005). Economic natural resource deposits at terrestrial impact structures. Geological Society, London, Special Publications, 248(1), 1-29. https://doi.org/10.1144/GSL.SP.2005.248.01.01

Heinrichs, T., Salameh, E., \& Khouri, H. (2014). The Waqf as Suwwan crater, Eastern Desert of Jordan: Aspects of the deep structure of an oblique impact from reflection seismic and gravity data. International Journal of Earth Sciences, 103(1), 233-252. https://link.springer.com/article/10.1007/s00531-013-0930-4

Hijmans, R. J., Cameron, S. E., Parra, J. L., Jones, P. G., \& Jarvis, A. (2005). Very high resolution interpolated climate surfaces for global land areas. International Journal of Climatology: A Journal of the Royal Meteorological Society, 25(15), 1965-1978. https://doi.org/10.1002/joc.1276

Koeberl, C. (2004). Remote sensing studies of impact craters: How to be sure? Comptes Rendus Geoscience, 336(11), 959-961. https://citeseerx.ist.psu.edu/viewdoc/download?doi=10.1.1.463.4948\&rep=rep1\&ty pe $=$ pdf

Koeberl, C., Reimold, W. U. (2005). Bosumtwi impact crater, Ghana (West Africa): An updated and revised geological map, with explanations. Jahrbuch der Geologischen Bundesanstalt.

Mars, J. C., \& Rowan, L. C. (2011). ASTER spectral analysis and lithologic mapping of the Khanneshin carbonatite volcano, Afghanistan. Geosphere, 7(1), 276-289. https://doi.org/10.1130/GES00630.1

Daneshvar, M. R. M., \& Bagherzadeh, A. (2013). Geomorphological investigation of possible impact evidences for the crater-shaped structure of Zirouki in Samsour Desert, SE Iran. Earth Science Informatics, 6(4), 241-252. https://link.springer.com/article/10.1007\%2Fs12145-013-0125-3

Paillou, P., Rosenqvist, A., Malezieux, J. M., Reynard, B., Farr, T., \& Heggy, E. (2003). Discovery of a double impact crater in Libya: The astrobleme of Arkenu. Comptes Rendus Geoscience, 335(15), 1059-1069. https://doi.org/10.1016/j.crte.2003.09.008

Paillou, P., El Barkooky, A., Barakat, A., Malezieux, J. M., Reynard, B., Dejax, J., \& Heggy, E. (2004). Discovery of the largest impact crater field on Earth in the Gilf Kebir region, Egypt. Comptes Rendus Geoscience, 336(16), 1491-1500. https://doi.org/10.1016/j.crte.2004.09.010

Passchier, C. W., \& Williams, P. R. (1989). Proterozoic extensional deformation in the Mount Isa inlier, Queensland, Australia. Geological Magazine, 126(1), 43-53. https://doi.org/10.1017/S0016756800006130

Pati, J. K., \& Reimold, W. U. (2007). Impact cratering-Fundamental process in geoscience and planetary science. Journal of Earth System Science, 116(2), 81-98. https://link.springer.com/article/10.1007\%2Fs12040-007-0009-3 
Pati, J. K., Prakash, K., \& Kundu, R. (2009). Terrestrial impact structures and their confirmation: Example from Dhala structure, central India. Earth Science India, 2(3), 289-298. http://www.earthscienceindia.info/pdfupload/tech_pdf-45.pdf

Raymond, O. L., \& Retter, A. J. (2010). Surface geology of Australia 1:1,000,000 scale, 2010 edition [Digital Dataset]. Geoscience Australia. https://researchdata.edu.au/surfacegeology-australia-2010-edition/340646

Reimold, W. U., Trepmann, C., Simonson, B., Sisodia, M. S., Lashkari, G., \& Bhandari, N. (2006). Impact origin of the Ramgarh structure, Rajasthan: Some new evidences. Journal of Geological Society of India (Online archive from Vol 1 to $\mathrm{Vol}$ 78), 68 (Special Issue 3), 561-565. http://ischolar.info/index.php/JGSI/article/viewFile/83655/73708

Schmieder, M., Seyfried, H., \& Gerel, O. (2013). The circular Uneged Uul structure (East Gobi Basin, Mongolia)-Geomorphic and structural evidence for meteorite impact into an unconsolidated coarse-clastic target? Journal of Asian Earth Sciences, 64(5), 58-76. https://doi.org/10.1016/j.jseaes.2012.11.042

Tucker, R. T. (2014). Stratigraphy, sedimentation and age of the upper cretaceous Winton formation, central-western Queensland, Australia: implications for regional palaeogeography, palaeoenvironments and Gondwanan palaeontology. Doctoral dissertation, James Cook University. https://researchonline.jcu.edu.au/34439/

Wang, J., Cheng, W., Luo, W., Zheng, X., \& Zhou, C. (2017). An iterative black top hat transform algorithm for the volume estimation of lunar impact craters. Remote Sensing, 9(9), 952. https://doi.org/10.3390/rs9090952

Wikipedia. (n.d). List of impact craters on earth. https://en.wikipedia.org/wiki/List_of_impact_craters_on_Earth

Wikiwand. (n.d). http://www.wikiwand.com/en/

Wright, S. P., Tornabene, L. L., Ramsey, M. S., Osinski, G. R., \& Pierazzo, E. (2013). Remote sensing of impact craters. In Impact cratering: Processes and products (pp. 194-210). Wiley-Blackwell. 